\section{LA HUMILDAD DE LA FENOMENOLOGÍA}

\author{
José Ruiz Fernández \\ Profesor Titular de la Facultad de Filosofía \\ de la Universidad Complutense de Madrid \\ jose.ruiz@filos.ucm.es
}

\section{THE HUMILITY OF PHENOMENOLOGY}

\begin{abstract}
From our current situation and looking at the future this essay tries to think what is the possible significance and value of Phenomenology. It will be sustained that there is a genuine necessity of Phenomenology. This necessity, I contend, arises from the rational humility that is idiosyncratic to it. Effectively, the exposition makes clear that, beyond any particular conception of how phenomenology is to be concretely accomplished, humility determines phenomenology as a rational endeavor practically deployed. The practical need of phenomenology is identical with the practical need of such a rational humility.
\end{abstract}

KEY WORDS: Phenomenology, humility, theory of reason.

Querría tratar aquí, de una manera directa, el problema en torno a la vigencia y necesidad de la fenomenología. Vaya dicho, de entrada, que no voy a discutir las ideas que en torno a la idiosincrasia del quehacer fenomenológico haya podido hacerse tal o cual pensador. Supongo, por lo pronto, que hay algo así como una "tradición fenomenológica" que, retrotrayéndose en cierta manera a la obra de Husserl, se prolonga, sin embargo, en líneas de fuerza que complementan, corrigen y critican, en aspectos a veces fundamentales, la fuente de inspiración primigenia y las prolongaciones posteriores. Lo que aquí querría considerar, por tanto, es si esa supuesta "tradición fenomenológica" es en verdad necesaria y por qué.

Como unas consideraciones tan breves como éstas no pueden demorarse con la debida calma en cuestiones fundamentales, ellas están próximas a parecer mera opinión personal que se expresa sin muchos miramientos. Asumiendo que esto es en buena medida inevitable, se tratará, con todo, que haya un acercamiento real a algunos problemas que la fenomenología suscita hoy.
RESUMEN: Con la mirada orientada al presente y al futuro en este ensayo se trata de pensar cuál sea la posible vigencia de la fenomenología. Se defiende que hay una efectiva necesidad práctica de la fenomenología que emana de la humildad que le es propia en tanto que quehacer racional particular.

PALABRAS CLAVE: Fenomenología, humildad, teoría de la razón.

En mi exposición adoptaré al principio un punto de vista externo tratando de subrayar al máximo aquellos motivos que parecen amenazar la pretensión de que la tradición fenomenológica tenga un cometido "vivo" por cumplir, que ella tenga verdaderamente algo que ofrecernos.

\section{INCERTIDUMBRES EN EL HORIZONTE}

El futuro histórico de la fenomenología, tal y como se lo representaba Husserl, no se ha cumplido. Como cuestión de hecho, esto es tan patente, salta tanto a la vista, que no parece siquiera pertinente entrar aquí en muchas matizaciones. La fenomenología eidético-trascendental era una tarea destinada a desarrollarse progresivamente por generaciones de investigadores en un trabajo comunitario; se presentaba como un quehacer que progresaría sobre un suelo de evidencias originarias; había de ser ciencia en el sentido más riguroso imaginable: conocimiento allende todo supuesto que habría de rendir un último fundamento para las "ciencias particulares"1. El contraste que la 
realidad fáctica ofrece a este respeto es descarnado. No se trata sólo de que en la tradición fenomenológica no haya algo parecido a un cuerpo de conocimiento asentado que se amplíe acumulativamente al modo de las ciencias formales e incluso empíricas. A decir verdad, ni siquiera la pretensión de alcanzar tal cosa es ahora dominante en esa tradición. Los pensadores inspirados por la obra de Husserl que ahora reciben mayor consideración se oponen, de distinta manera y casi sin excepción, a las pretensiones fundamentales que, a este respecto, alentaba el pensamiento del maestro. Podría decirse, exagerando un poco, que el rechazo a la fenomenología, entendida como pretensión de ganar una ciencia universal, es general. $Y$ ya sin exageración, que esa pretensión, en la medida en que sigue viva, es minoritaria, y no ofrece frutos exentos de controversia.

De la fenomenología solemos hablar ahora con gran equivocidad. Tenemos el idealismo trascendental de Husserl y la hermenéutica fenomenológica de Heidegger; tenemos la fenomenología material de Michel Henry y la obra de Levinas. El realismo de las esencias y la fenomenología de la donación. Sartre, Merleau-Ponty, Patočka... cada autor asume una orientación original que, en un plano fundamental, podría contraponerse al resto. La fenomenología, según parece, "se dice de muchas maneras". Esta pluralidad de orientaciones no sólo puede promover la desorientación sino que, también, parece fomentar un cierto escolasticismo. Uno es seguidor de Husserl o de Heidegger. De tal o cual autor. Se hacen congresos sobre autores particulares que invitan a permanecer dentro de los supuestos fundamentales que a él son inherentes. 0 se puede tratar alternativamente sobre autores que mantienen posiciones irreconciliables sin que esto suscite problemas mayores. Aunque haya una conciencia difusa de que uno se mueve dentro de una "tradición fenomenológica común", no siempre se ve del todo claro en qué sentido es esto así. Parece haber suficientes razones para cuestionarse si esa tradición no estará conformada, a la postre, por una pluralidad de teorías distintas que mantienen sólo el vínculo externo que da ciertas lecturas compartidas y el uso más o menos común de una terminología técnica que, por lo demás, viene a cobrar un relieve variable según el autor considerado. Uno puede verse tentado a pensar que la fenomenología vive ahora, no en la forma de un "desarrollo histórico común", como quería Husserl, sino, más bien, en la forma de una "preservación histórica común".
Igual de incierto debe parecer a muchos el sentido práctico que pueda guardar ese "quehacer" que se pone en obra en la tradición fenomenológica. En la creencia de servir al establecimiento de verdades eternas, Husserl veía en la fenomenología el desarrollo, si no el cumplimiento, de la tendencia del hombre a la libre posesión de sí. La fenomenología servía al cumplimiento de un telos inmanente al hombre: la fenomenología era teoría pura pero, por eso mismo, estaba henchida de sentido práctico para un sujeto que en su actividad y habitualidad se pensaba teleológicamente atravesado de razón ${ }^{2}$. En la medida en que una fenomenología sub specie quadam aeternitatis parece hacer aguas, el sentido práctico del quehacer fenomenológico se torna, al pronto, algo problemático. Uno puede afanarse privada y denodadamente en el "trabajo fenomenológico" $y$, sin embargo, no estar en claro para qué y con qué fin lo hace. La idea de que un trabajo de matización y distinción, prolongado al infinito por distintos caminos, coadyuve a la plena realización práctica del hombre parece a muchos, y no sobran razones que oponer a esto, bastante quimérica. Uno podria verse tentado a pensar que la fenomenología no es sino un juego entretenido, problemático y a ratos agotador, pero nada más.

Husserl estaba seguro de la dignidad de la ciencia universal porque, creía, ella hace últimamente posible el desarrollo de "una autonomía personal y humana omniabarcante" 3 cuya bondad no se discutía. Por eso afirmaba el superior valor de la fenomenología frente a esa filosofía de la cosmovisión que hace uso de los "recursos racionales" que están al alcance para proveer al hombre de metas e ideales finitos ${ }^{4}$. Como el carácter supratemporal del quehacer fenomenológico se ha tornado dudoso, brota ahora la tentación de justificarlo haciendo de ese quehacer un medio con el que promover los fines prácticos que más nos preocupan: partimos de distinciones atenidas a ciertas experiencias particulares y tenemos prisa por aventurarnos a hacer diagnósticos sobre casi todo: la tecnificación, la globalización, la presunta o real deshumanización de la cultura occidental, la pérdida de Dios, etcétera. Cuando desde una orientación pretendidamente fenomenológica se tratan temas de "orden práctico" o "religiosos", a veces parece que lo que marca la pauta del discurso es el deseo de "abogar" por ciertas posiciones. Uno tiene que preguntarse entonces si lo que ahí se ofrece va más allá de un fondo de opinión, más o menos sugerente y problemático, pero en modo alguno distinto del que habitualmente rodea 
a ese tipo de cuestiones. La aparente profundidad con la que algunas reflexiones se invisten parece hecha sólo del ropaje de una terminología técnica. Creo que no faltan razones para pensar que demasiado a menudo se hace pasar por fenomenología formas de discurso que sólo tienen la dudosa virtud de persuadir acerca de aquello que el autor tenía el deseo de hacer valer, aunque de una manera considerablemente menos clara y efectiva que la que el lenguaje común hace de suyo posible. Aun sin tener que asumir que tales formas de discurso sean las dominantes, el hecho de que ellas tengan cierta cabida en la tradición fenomenológica, ¿no es prueba y reflejo de que el quehacer fenomenológico mismo se ha tornado problemático?

A todo lo anterior cabria oponer, sin embargo, la distinción husserliana entre el hecho histórico de la filosofía y la filosofía como idea ${ }^{5}$. La fenomenología como hecho histórico podrá tener sus caídas y bajadas de nivel. La fenomenología como idea espera un cumplimiento posible y, racionalmente, no puede sino prevalecer. Esta distinción nos ayuda muy bien a disolver el efecto corrosivo que pueden promover algunas decepciones particulares, como las inmediatamente comentadas. Efectivamente: si podemos advertir ciertas deficiencias racionales en el quehacer fáctico que se pretende fenomenológico, eso mismo es la prueba de que algo así como un quehacer originariamente fenomenológico nos requiere. Hay en esto, sin duda, cierta verdad. Lo que no está tan claro, sin embargo, es que aquello que nos requiere venga a cifrarse en el ideal particular bajo el que Husserl pensaba el quehacer fenomenológico. No está claro que ese ideal sea racionalmente congruente. En la tradición fenomenológica se ha realizado una purga, amparada en motivos fenoménicos concretos, que han tornado problemática la pretensión de que la fenomenología pudiera realizarse en la forma de un cuerpo teórico establecido y fijado esencialmente de una vez por todas. ¿Qué cumplimiento podría tener ese ideal cuando el medio discursivo en que habría de venir a realizarse se mueve de manera insuperable en un horizonte histórico? Adviértase que lo que aquí se pone de relieve no es un mero escollo fáctico en relación a un ideal infinito, sino una imposibilidad esencial, constitutiva, por relación a un ideal como tal ideal. Por otra parte, si consideramos que ese ideal apunta a una elaboración categorial mediata y derivada de aquello que antes de toda teoría nos es concretamente patente, ¿no produciría el predominio de ese ideal una logificación que nos apartaría, justamente, de lo fenoménicamente concreto? ¿No tenemos entonces razones internas para pensar que ese ideal no es posible, más aún, que ni siquiera coincide con la fenomenología entendida formalmente como discurso que guarda originariamente los fenómenos?

Con la disolución, no sólo histórica sino también interna, de la idea bajo la que la fenomenología fue concebida por su "fundador", es normal que el problema acerca de la vigencia y sentido del quehacer fenomenológico se torne acuciante. Como rechazo al escepticismo y relativismo hermenéutico que nos amenazan, podríamos desear aferrarnos nominalmente a ese ideal primigenio dejando de lado aquellos problemas con los que no sabemos bien qué hacer. Esto, sin embargo, tendría el sentido de una claudicación racional. No es que el sentido del quehacer fenomenológico pueda presentársenos como problema, es que tiene que presentársenos como problema si en verdad no renunciamos a la pretensión fenomenológica.

Asumiendo plenamente esto último creo, con todo, que la fenomenología sigue constituyendo el índice de una tarea, no sólo vigente, sino enteramente necesaria. A continuación trataré de apuntar rápidamente por qué pienso que esto es así.

\section{La humildad de La fenOMenología}

Abandonemos nuestra perspectiva externa y tratemos de hacer un esfuerzo por discernir aquello que intimamente pueda ser característico al quehacer fenomenológico. Hablamos en forma amplia de la fenomenología. ¿A qué nos referimos con ello? ¿Acaso a un método que Husserl desarrollara en la forma de un análisis eidético de los rendimientos de sentido de una conciencia trascendental sujeta a un orden genético-constitutivo? Ciertamente no. De la misma manera que Husserl varió su posición a lo largo del tiempo, nada nos impide pensar que, de haber continuado su tarea, hubiera podido llegar a criticar, por razones internamente fenomenológicas, la concepción que dio en asumir de la fenomenología. Adviértase ya que hablamos aquí de algo así como "razones internamente fenomenológicas" que quedan a salvo de la concepción particular que uno pueda estar haciéndose del quehacer fenomenológico. Esto es, por cierto, bastante habitual entre 
los pensadores que asumen su tarea como fenomenológica. Sus concepciones particulares de la fenomenología pueden estar decididamente en pugna entre sí. Sin embargo están en pugna por razones fenomenológicas. La pugna denuncia una comunidad no cuestionada. Los fenomenólogos están hermanados en un mismo quehacer con aquel al que critican. Este hermanamiento es, a pesar de las discrepancias, o mejor, justamente por ellas, algo enteramente real para ellos. ¿En qué se cifra? A mi entender, tan sólo en esto: la asunción compartida de que la legitimidad del discurso descansa originariamente en los fenómenos; que son los fenómenos los que han de dirimir acerca de la legitimidad; que ninguna teoria puede imponerse sobre ellos so pena de dogmatismo. La pretensión de dar cuenta de los fenómenos sometiéndose enteramente a ellos es, en verdad, el principio fenomenológico: el único principio que legítimamente podria imperar en el orden de las razones porque no impone ningún esquema teórico sino la precedencia de lo que es patente sobre todo esquema teórico.

Lo que acabamos de decir nos es, en cierta manera, consabido; sin embargo, no siempre advertimos con claridad su alcance. Inmediata consecuencia de ello es que ha de repugnar al quehacer fenomenológico asumirse a manera de un cuerpo teórico o método previamente fijado. Heidegger decía que "lo esencial de la fenomenología no consiste en ser una 'corriente' filosófica real"'. Con ello afirmaba algo que puede oponerse a ciertas formulaciones en las que Husserl expresa su concepción particular de la fenomenología, pero también algo que constituye lo más propio del pensamiento husserliano, a saber, la voluntad de supeditarse a los fenómenos, antes de toda teoría. Puede decirse que, antes de toda concepción particular del quehacer fenomenológico, la pretensión de la fenomenología se cifra en realizar un discurso enteramente sometido a los fenómenos. Ese problemático pero inexcusable sometimiento es el verdadero principio que antecede a todo principio teórico y es lo que da la medida del carácter fenomenológico de un pensador. Antes que la formulación de un sistema, la fidelidad discursiva a aquello de que concretamente se trata es lo que en el quehacer fenomenológico tiene que realizarse. Por eso, uno puede sentirse hermanado con el meollo del pensamiento husserliano o heideggeriano, por ejemplo, más aún, ver en esos pensadores una cima fenomenológica ejemplar, $y$, sin embargo, guardar respecto a ellos una distancia crítica hecha, justamente, de motivos formalmente fenomenológicos. Por eso, también, uno puede adherirse a una pretensión fenomenológica a la vez que advierte que su realización concreta es un problema necesitado, todavía, de clara dilucidación, es decir, de una dilucidación originariamente fenomenológica.

Porque el sometimiento a los fenómenos impera en el quehacer fenomenológico podemos decir que la fenomenología es una tarea que está constitutivamente atravesada de humildad. No decimos esto con ánimo metafórico sino con la intención de distinguir algo en verdad inherente a la fenomenología como ejercicio racional concreto. Trataré de aclarar por qué digo esto. Como toda tarea racional en general, la fenomenología se lleva a cabo de manera próctica, es decir, en un ejercicio en el que ponemos en juego nuestra libertad. Por otra parte, y como pasa con toda tarea racional imaginable, la fenomenología ha de realizarse en el medio del discurso. Pero el quehacer fenomenológico tiene de específico lo siguiente: que el único principio que verdaderamente determina su ejercicio es el sometimiento a los fenómenos. La matemática, la física, la historia, la sociología o la teoría política también tienen que atenerse en cierta manera a los fenómenos. Sin embargo, ese atenerse tiene lugar en el marco de propósitos y pretensiones determinadas. El quehacer fenomenológico, sin embargo, no tiene propósitos allende su pretensión de guardar lo fenoménicamente concreto. Es decir, en principio, la fenomenología no es una tarea que se sirva de los fenómenos con el fin de establecer o descubrir racionalmente "algo"; al menos no al modo que la física, la matemática o la sociología, pongamos por caso, tratan de llegar a "algo nuevo" que, en principio, no nos está dado. Lo que el quehacer fenomenológico realiza no es una elaboración discursiva de los fenómenos en pos de un fin extrínseco a ellos sino la preservación discursiva de los fenómenos. Pero esto es enteramente peculiar. Sucede aquí, efectivamente, que un quehacer discursivo se pone en obra no, primariamente, con vistas a establecer tales o cuales resultados sino con vistas a hacer valer los fenómenos, esto es, aquello de lo que quizá no nos hemos "dado cuenta" discursivamente, pero aquello que es patente antes de toda tarea discursiva. La pretensión fenomenológica impele a que su discurso venga a asumir su carácter subalterno en relación con los fenómenos, sin imponerse sobre ellos. Lo discursivo-significativo tiene en la fenomenología que quedar preterido en relación con aquello de lo que concretamente se ocupa ese discurso. Que el ejercicio fenomenológico conlleve una renuncia a la autonomía discursiva, esto es, renuncia a 
imponerse sobre aquello de que concretamente se trata, hace que la humildad sea constitutiva a esa posibilidad racional particular que es la fenomenología.

Algunos de los rasgos que más Ilaman la atención de la práctica fenomenológica, en contraste con otras "tareas racionales", no son, me parece, sino trasunto de esto que se acaba de decir. Un primer reflejo de la humildad fenomenológica es su afán por demorarse en matizaciones y distinciones que recojan y guarden la riqueza de lo dado sin vencerse a la tentación de reducido y "darlo por sabido". En la fenomenología no hay prisa porque no se trata en ella de alcanzar un orden teórico-sistemático con el que subsumir lo dado. La inquietud que la fenomenología provoca en algunos filósofos es la impaciencia del que quiere estar en posesión de un "orden de verdades". Esa impaciencia normalmente acaba cristalizando en la forma de una "teoría global" que nos ofrece descanso porque nos da una respuesta para todo. A esta tentación la fenomenología opone su negativa a la imposición discursiva apresurada, un demorarse en lo fenoménicamente concreto para hacerlo valer a salvo de toda consideración parcial. Al distinguir aquello que solemos pasar por alto ganamos la posibilidad de "darnos cuenta" de una realidad fenoménica que es más rica que aquella que domina en el discurso de otras tareas racionales orientadas a fines particulares. Quizá nadie como Husserl ha cumplido esto. En su pulcritud, en su increible capacidad para fijar distinciones atenidas a la experiencia concreta, se encarna, podría decirse, esa humildad del discurso abierto que se atiene a aquello de que concretamente se trata sin más pretensión que esa. Con esto que decimos está relacionado, también, que el quehacer fenomenológico no pueda aventurarse a ofrecer "recetas prácticas" so pena de dejar de ser lo que ella es. La fenomenología tiene un sentido práctico, ya lo veremos, pero ese sentido tiene que realizarse como puro afán racional por guardar lo fenoménicamente concreto, es decir, desde la humildad que es inherente a su ejercicio y no de otra manera. Esta humildad no es fácil y, por eso, el ejercicio de la fenomenología está constantemente expuesto a la tentación de edulcorarse en aras a servir a otros propósitos. Pedir orientación práctica al quehacer fenomenológico es, casi siempre, una invitación a hacer otra cosa que fenomenología. Aceptar esa invitación $y_{\text {, }}$ sin embargo, pretender que uno sigue cumpliendo una pretensión fenomenológica es engañarse o ceder a una forma de soberbia racional.
Un segundo rasgo, también muy apreciable en la práctica fenomenológica, es la tendencia a que en ella el discurso fenomenológico disuelva su rigidez, se torne metafórico y ponga distancia frente a su literalidad. Esto no tiene nada que ver con el "capricho creativo" y el "deseo de oscuridad", cosas ambas que están en las antípodas del propósito interno que anima el quehacer fenomenológico. Lo que sucede es que la pretensión fenomenológica impele a protegerse contra la tendencia de que su propio discurso se torne "la cosa misma" de que se trata. Las distinciones han de servir para darnos cuenta de una concreción de sentido que las antecede. Por eso, es habitual que ellas se presenten con la constante advertencia de que no pueden asumirse en su autonomía ni en una rigidez objetiva. Las distinciones conviven constantemente con la remisión al ejemplo $y$, en definitiva, con la remisión a la concreción primigenia que toda distinción categorial o esencial supone: se trata en definitiva de "la cosa misma", no del plano articulado del discurso que nos sirve meramente para dar cuenta de ella. Quizá en nadie como en Heidegger encontramos ese esfuerzo por substraer aquello que se está tratando a la tendencia objetivadora del discurso teórico. En la analítica existencial de Ser y Tiempo, por ejemplo, se ponen en juego abundantes recursos retóricos que coadyuvan a que las distinciones que se realizan queden, como si dijéramos, en sordina, de manera que se haga valer la concreción de aquello de que se está tratando sin dejar que esa concreción se disuelva en el horizonte discursivo en que las distinciones se mueven. De esto mismo surge la resistencia a que el quehacer fenomenológico se anquilose en la forma rígida de un sistema teórico, científico. Uno podría pensar que este segundo rasgo del quehacer fenomenológico es antitético con el que antes hemos introducido. Esa creencia, sin embargo, se alimenta de una apreciación superficial. La tendencia fenomenológica a la distinción pormenorizada y la tendencia fenomenológica a la disolución de las distinciones en la concreción que ellas suponen brotan de una misma raíz. La distinción pormenorizada introduce discursivamente lo concreto, nos permite "darnos cuenta" de los fenómenos; la disolución aclara en su concreción aquello de lo que nos damos cuenta: una cosa y otra nacen de un mismo impulso, a saber, el humilde afán racional de dar cuenta de los fenómenos sometiéndonos enteramente a ellos.

La peculiar humildad racional de la fenomenología nos ayuda a entender algo que, al parecer, es también un rasgo

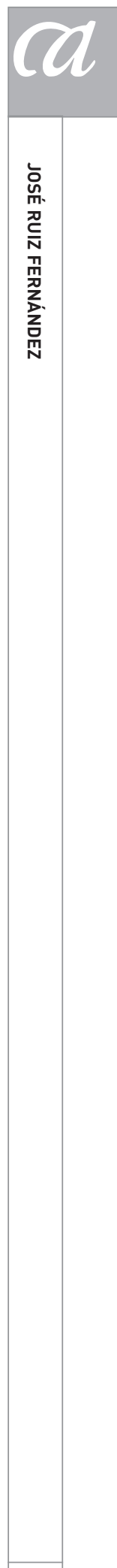


característico de la tradición fenomenológica, a saber, la pugna constante entre distintas concepciones fenomenológicas. A poco que uno trate de situarse históricamente ante este hecho advierte que la cosa es enteramente excepcional. Creo que difícilmente se encontrará en la historia de la filosofía un caso como éste, a saber, una tradición de pensamiento que no ha dejado en ningún momento, y esto desde el principio, de ponerse absolutamente en cuestión. Los desacuerdos en fenomenología no tocan cuestiones particulares dentro de una ortodoxia establecida sino que atañen a todos sus conceptos fundamentales. Los fenomenólogos no dejan de cuestionarse por el sentido que originariamente guarda la apelación al fenómeno, a la intencionalidad, a la significación. Más aún, por el sentido del quehacer fenomenológico mismo. Aquello mismo que está en obra es radicalmente problema. Una tradición de pensamiento que se sostuviera en un conjunto de tesis establecidas no podría nunca mantenerse asi: entraría en crisis. La tradición fenomenológica puede realizarse de esa manera porque no "vive" internamente de una concepción establecida sobre su propio quehacer sino de algo a lo que cualquier concepción particular de la fenomenología está obligada a servir hasta el punto de tener que abandonarse, a saber, el sometimiento a los fenómenos. Algo de esta índole, es decir, un quehacer racional que no se impone en modo alguno sino que constantemente está abierto a lo efectivamente problemático hasta el punto de tener que comenzar siempre de nuevo, supone humildad: la fenomenología está en obra, no por las concepciones que hace de sí misma, sino en tanto que quehacer discursivo que se somete fielmente a los fenómenos sin imponerse "porque si" como una forma de ideología. Lo que hermana a la tradición fenomenológica, ya lo hemos dicho, no es ninguna tesis material sino el principio fenomenológico antes de toda tesis. El hecho de que la tradición fenomenológica se mantenga en tensión constante respecto a sí misma es, pues, algo que brota de su idiosincrasia más propia y no debe constituir para ella un motivo de preocupación. Mientras esa tensión sea real, es decir, mientras se alimente de una lucha concreta, eso querrá decir que la tradición fenomenológica está efectivamente viva. Su interna degeneración sólo podría producirse, me parece, de dos maneras: por su abandono en un ejercicio caprichoso que se afana en una originalidad vacía, es decir, por soberbia racional, y por su abandono en un escolasticismo satisfecho, es decir, por renuncia a la pretensión que la constituye.
El lector podrá advertir ya por qué pienso que las consideraciones que en el primer punto se hicieron no ponen en cuestión la vigencia del quehacer fenomenológico y, menos aún, el interno propósito que anima a ese quehacer. Algunas de las incertidumbres que alli expusimos tocaban síntomas de efectivo decaimiento pero, en la medida en que esto era así, apuntábamos motivos que el cabal ejercicio de la fenomenología no promueve sino que empuja a eliminar. Por lo demás, es fácil comprender que el ejercicio fenomenológico más propio parezca a algunos un quehacer vano. Ese equívoco surge cuando él se considera a la luz de un ideal científico de conocimiento que, siendo mero índice de un cometido racional particular, ejerce socialmente una influencia dominante.

A poco que escarbemos en ese equívoco se insinuará la efectiva necesidad de la fenomenología. A esta cuestión, que es la que inicialmente nos propusimos, vamos ahora a acercarnos.

\section{LA NECESIDAD DE LA FENOMENOLOGía}

Lo que prácticamente rinda el quehacer fenomenológico no puede brotar de su utilización interesada para fines que le son extrínsecos sino del puro ejercicio de la pretensión que lo constituye. La pretensión de la fenomenología se cifra, ya lo hemos apuntado, en desplegar un discurso en el que, ante todo, sean los fenómenos los que se hagan valer. Esta pretensión presenta, al pronto, un cariz paradójico. Al fin y al cabo, los fenómenos son patentes hagamos fenomenología o no la hagamos. ¿Por qué es necesario un discurso que los preserve? ¿Por qué ha de haber una tarea racional cuyo afán consista, no en rendir frutos nuevos al modo como la matemática o la física lo hacen, sino tan sólo, en dar cuenta de aquello, justamente, que es ya patente?

Reparemos, por lo pronto, en algo que antes se dijo de pasada: que la supeditación a los fenómenos que la fenomenología proclama como principio es, en cierta manera, algo inherente a toda tarea que, con buen sentido, podemos llamar racional. El físico puede interpretar el sentido empírico-teórico de una medida pero no podría modificarla a conveniencia si no quiere ser acusado de fraude. El matemático puede hacer progresar su trabajo 
en la variable composición de ciertos órdenes formales, pero no podría desentenderse de ellos para demostrar un teorema, pues la demostración no sería tal y quedaría invalidada. En todas las tareas que solemos Ilamar científicas pasa lo mismo: el sociólogo no puede cambiar los resultados que ofrecen las estadísticas, los historiadores no pueden modificar a conveniencia el contenido de los documentos, etcétera. Incluso en las formas comunes de discurso, estamos obligados a supeditarnos a los fenómenos mientras pretendemos hacer valer algo racionalmente. Una conversación o discusión, mientras mantiene viva una cierta pretensión de legitimidad racional, no puede llegar al punto en que pudiera decirse algo como: "las cosas son así pero no las acepto". Tal cosa significaría ipso facto la ruptura del diálogo en tanto que posibilidad racional. En general, dondequiera que el sometimiento discursivo a los fenómenos es transgredido a voluntad, ahi desaparece toda forma de racionalidad, científica o no. El sometimiento a los fenómenos no es un aditamento contingente a la concreta posibilidad de algo así como un juego discursivo racional, sino algo que está en la raíz de que esa posibilidad sea efectiva. Sin ese sometimiento una tal posibilidad se degrada y desaparece.

Todo quehacer racional se supedita, por tanto, en algún sentido, a los fenómenos. Ahora bien, salvo la fenomenología, lo que orienta a las tareas racionales no es esa supeditación en cuanto tal, es decir, la pretensión que las anima no es la de guardar lo que es concretamente patente sino la de llegar a algo nuevo: en ellas se trata de rendir prácticamente algo. En general, lo que motiva y orienta una tarea racional no es la pretensión de guardar los fenómenos sino de alcanzar algo que inmediatamente no está dado. En las tareas racionales se trata, normalmente, de rendir prácticamente algo. Por ejemplo, las relaciones que el matemático constata no están dadas de antemano sino que tienen que ser fijadas al hilo del quehacer matemático mismo. En otras palabras: esas relaciones sólo cobran realidad en el concreto despliegue categorial matemático. Un tal quehacer discursivo es efectivamente racional pero él no busca meramente la supeditación a lo compareciente sino rendir algo que inmediatamente no comparece. $Y$ a eso, efectivamente, se llega, pero se llega sólo cuando "nos ponemos a ello" en un quehacer racional que tiene que ser prácticamente desplegado. De igual manera, la ciencia empírica, por ejemplo la física matemática, es inherentemente creativa, es decir, es un quehacer racional que apunta, no a la preservación del sentido perceptivo, sino a ganar una orientación y previsión mundano-objetiva máximamente simple y abarcante, a saber, algo que inmediatamente no nos es dado en modo alguno. Si en el horizonte del mundo queremos alcanzar ese fin, es decir, un dominio categorial desde el que prever y anticipar la acción con seguridad objetiva, entonces tenemos que hacer física. Aquello de que se trata sólo gana concreta realidad por el despliegue de la tarea racional misma. Despliegue que aquí cobra forma en la proyección de un orden matemático componible y de principios generales que permiten cuestionar y poner empíricamente a prueba de una manera controlada. La ganancia que con ello se alcanza es enteramente real: ganamos un nuevo poder de previsión con el que pasamos a contar en nuestra concreta inserción discursiva en el mundo. Consideraciones análogas a las que acabamos de hacer pueden extenderse a todas las tareas que tenemos por "científicas" y más allá. Esas tareas se mueven en un cierto avenimiento a los fenómenos, es decir, son racionales, pero ellas están prácticamente orientadas y motivadas por la prosecución práctica de ciertos fines a los que sirven: fines a los que ellas y sólo ellas pueden dar cumplimiento en su despliegue concreto. Todas esas tareas particulares se legitiman prácticamente en la prosecución creativa de los fines a los que sirven. La fenomenología, sin embargo, es la única tarea racional que no trata de rendir creativamente resultados. En ella no se trata de ganar posibilidades nuevas ni de establecer "algo nuevo" que no sea concretamente patente, sino de dar cuenta de lo que es concretamente patente sometiéndose enteramente a ello. Se agudiza, entonces, nuestro problema: ¿por qué es ella entonces necesaria?

Las distintas tareas racionales, hemos dicho, tienen que supeditarse, en cierta manera, a los fenómenos, pero no ponen su celo en esa sumisión sino que están encaminadas a la prosecución de los fines particulares que les son propios, encaminadas, por tanto, a rendir resultados que ellas hacen valer discursivamente. Ahora bien, surge aquí un peligro: en la prosecución del fin al que sirven, esas tareas desatienden cualquier realidad concreta ajena a su cometido y tienden a imponer sus resultados como la determinación originariamente verdadera y únicamente relevante de lo real. Cuando esto pasa, es decir, cuando, en su discurso, esas tareas acaban por subsumir la concreción fenoménica a la que, en cuanto racionales, estaban sometidas, se produce una particular forma de

ARBOR CLXXXV 736 marzo-abril [2009] 379-387 ISSN: 0210-1963

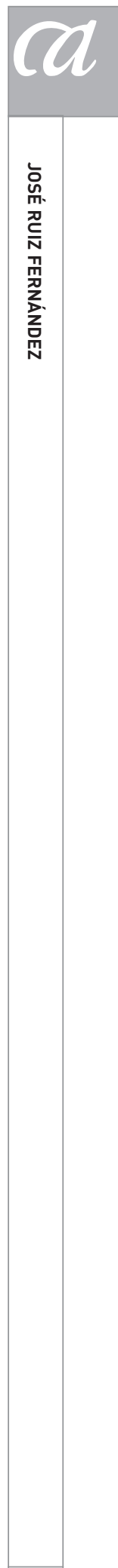

385 
trasgresión racional. El discurso funciona entonces como ideología, es decir, como un medio que se impone en su autonomía y que nos domina como aquello que vale para nosotros originariamente. El normal juego racional queda entonces comprometido por discursos que, en diversas formas, tienden a reducir la realidad y a determinarla dogmáticamente como totalidad. A esta forma de dominio las distintas tareas racionales no pueden hacer frente por sí mismas. En su ejercicio ellas bien podrían contribuir a acrecentar su arraigo y extensión. Con una excepción. La fenomenología es la tarea racional que hace de la supeditación a los fenómenos su principio y su fin. Si en el quehacer discursivo fenomenológico sólo se trata de preservar aquello que está concretamente dado ese ejercicio es, por tanto, el que debe acometerse para poder salir de esa situación.

Es un contrasentido pensar que la fenomenología está para establecer un "fundamentos absoluto" que pueda hacerse valer de manera vinculante sobre toda tarea racional particular. En la medida en que esto ha pasado en la tradición fenomenológica, ha sucedido porque ella ha caído presa del peligro mismo que está llamada a combatir. El quehacer fenomenológico no puede servir para dar un fundamento a aquellas tareas que sólo pueden cumplirse en un ejercicio práctico orientado a fines. Tampoco, ciertamente, para imponer un esquema con el que subsumir de manera absoluta aquello que ya de entrada nos es patente. Su tarea es mucho menos aparente, mucho más humilde. Su discurso no tiene, en verdad, nada nuevo que ofrecer. La humildad de la fenomenología, sin embargo, es una necesidad interna al juego racional para que éste no degenere, para que no termine por convertirse en un automatismo ciego y en el medio del dominio ideológico. Mantener viva una cierta tensión fenomenológica es enteramente fundamental para la concreta pervivencia de un juego efectivamente racional. En la fenomenología no se trata, por tanto, de aparentar una humildad impostada $y$, mucho menos, de entretenerse con un intelectualismo vacuo: su humildad es algo requerido para el cabal mantenimiento de un juego discursivo racional. Por eso, en un sentido amplio, el quehacer fenomenológico ha estado vivo desde hace mucho tiempo. Ha estado vivo en el quehacer filosófico que ha tratado de distinguir la inagotable riqueza de lo real, y en el poema que guarda la concreción de aquello de que da cuenta sin someterlo a esquemas rígidos. De manera más o menos realizada ha vivido siempre en múltiples formas de discurso. Si se puede hablar de Husserl como punto de referencia capital en la fenomenología eso se debe, antes de nada, a que en su pensamiento, más que un cierto método o conjunto cerrado de tesis, se echa de ver una tensión constantemente renovada por plegarse a los fenómenos de una manera ejemplarmente responsable y honesta. Aunque en su pensamiento algunos motivos nos puedan parecer discutibles, no podemos dejar de sentirnos hermanados con la tensión práctica que lo anima y que su obra tan vivamente trasluce.

No hay que poner mucho cuidado en justificar la vigencia de la fenomenología alegando méritos particulares: en verdad, ella será siempre índice de una tarea irrenunciable para los hombres que, estando en el mundo, desplegando diversas tareas y dándose cuenta discursivamente unos a otros, quieren mantener discursivamente vivo aquello que en concreto les concierne. La tradición fenomenológica, sin embargo, tiene ante sí, me parece, importantes retos a fin de que su tarea no quede sin efecto. El peligro mayor que yo aprecio, a este respecto, es su tendencia a replegarse sobre si misma. Si la fenomenología fuera una tarea orientada a rendir resultados acumulativos, o a desentrañar un problema enrevesado y complejo, eso tendría algún sentido. Pero no es el caso. La cerrazón interna del quehacer fenomenológico, con el consiguiente desarrollo de recursos conceptuales especializados, tiene que producir, me parece, un cierto anquilosamiento. En tanto que la tradición fenomenológica asuma su quehacer como un propósito cerrado que tiene que ser cumplido por un grupo de especialistas, eso redundará en impropiedad y en una pérdida de su sentido práctico. Sólo hay, me parece, un problema que puede atañer en exclusiva al interés del "fenomenólogo de profesión": la clara dilucidación del sentido del quehacer fenomenológico. Una tradición fenomenológica necesita, efectivamente, claridad última en relación con el sentido concreto que tiene su propio quehacer. Pero una vez ganada esa claridad, los fenomenólogos son los que menos falta tienen de la fenomenología. Sería deseable, me parece, que el quehacer fenomenológico redundara, más bien, sobre aquellos que más lo necesitan, a saber, quienes se mantienen en la asunción dogmática, de ciertas formas de ideologia (relativismo, cientificismo, materialismo, fanatismo). Y si esto no es posible directamente, sí, al menos, sobre aquellos que imparten su magisterio en las distintas tareas racionales particulares. El quehacer fenomenológico está llamado a vivificar fenoménicamente 
el juego discursivo racional en el que estamos inmersos. Cómo y por qué cauces podría esto realizarse en el pre- sente es un problema práctico sobre el que no me atrevo ya a dar una opinión.

\section{NOTAS}

Recibido: 12 de noviembre de 2007 Aceptado: 15 de diciembre de 2007
1 "Sólo hay una única ciencia verdadera en el sentido más alto de la palabra, Ilamémosle filosofía o ciencia universal. Ciencias particulares siempre las habrá, naturalmente, con particulares ámbitos, métodos y técnicas teóricas, y presuponiendo dotes personales particulares... pero todas las ciencias particulares serán sólo órganos, aunque esencialmente unitarios, ramas vivas del árbol de la ciencia universal", E. Husserl, Natur und Geist, Husserliana Bd. XXXII, Kluwer Academia Publishers, 2001, pp. 17-18.
2 Vid. E. Husserl, Gesammelte Werke (Husserliana), Band VI: Die Krisis der europäischen Wissenschaften und die transzendentale Phänomenologie, Martinus Nijhoff, Haag, 1954, p. 272.

3 E. Husserl, Die Krisis der europäischen Wissenschaften, p. 273.

4 Vid. E. Husserl, Philosophie als strenge Wissenschaft, Vittorio Klosterman, Frankfurt am Main, 1965, p. 61.

5 Vid. E. Husserl, "Die Krisis des europäischen Menschentums und die Philosophie", en Die Krisis der europäischen Wissenschaften, p. 338.

6 M. Heidegger, Sein und Zeit, Max Niemeyer Verlag, Tübingen, 1993, p. 38. 